\title{
PRIMARY MELT INCLUSIONS IN ECLOGITE DIAMONDS AND THEIR GENETIC IMPLICATION.
}

P.G. Novgorodov.

Study of primary melt microinclusions in diamonds from the Vir pipe (Bulanova et al., I988; Novgorodov, Bulanova, I989; Novgorodor et al., I990) is very important for understanding petrological and geochemical aspects of mantle processes. These jorks, together with other published data, permit the following main conclusions regaraing genesis.

I. Nelt inclusions of andesite composition in diamunds are thought to represent a fragment of initial melting of diamondiferous mantle eclogites (Green. Ringwood, I968; Sobolev, Sobolev, I975). From data available, all calculated temperatures for the associrtion garnet/omphacite (IIIis, Green, Iy79, F=50 kb) of inclusions in diamonds from the Nir, Roberts Victor, Premier, orapa, Sloan kimberlites and Argyle lamproites fall in the interval detween he wet and dry soludus for eclogites on F-T diagrams. Diamondiferous eclogites probably experiencad partial uelting if they initially contained some volatiles $\left(\mathrm{H}_{2} \mathrm{O}, \mathrm{CO}_{2}\right)$.

2. I' appear 3 that a high-potassium melt represents a fragment of the final evolutionary stage of runtle eclogites. Its disproportionation might occur as follows: $\mathrm{mK}_{2} \mathrm{O} \cdot \mathrm{nNa}_{2} \mathrm{O} \cdot \mathrm{Al}_{2} \mathrm{O}_{3} \cdot$ $6 \mathrm{SiO}_{2} \cdot \nabla^{I} \rightarrow 2 \mathrm{mSa}+2 \mathrm{nJd} g s+[I-(m+n)] \mathrm{Ky}+5[I-(m+0.6 n)]^{2}$ $\mathrm{cs}+\mathrm{V}^{I I}$, where $\mathrm{v}^{I}=$ dissolved volatiles, $V^{I I}=$ fluid phase. The Iluid phase should be in equilibrium with the association $\mathrm{Gar}+\mathrm{Omph}+\mathrm{Sa}+\mathrm{Ky}+\mathrm{Cs}+\mathrm{Rut}+\mathrm{FeS}$. Xenoliths containing such a suite of minerals from Roberts Victor (Smith, Hatton, I977) and Udachnaya (Spetsius et al., I984) are likely to represent relics of similar processes that occurrad in the upper mantle. The above reaciion may explain transition from rutile eclogites into kyanite ones.

3. Fluid microinclusions in coated and cubic diamonds from Zaire and Botswana (Navon et al., I988, I989), which are enriched in $\mathrm{SiO}_{2}, \mathrm{~K}_{2} \mathrm{O}, \mathrm{TiO}_{2}$, FeO and trace elements, probably characterize the subsolidus evolutionary stage. Data on melt and fluid microinclusions, although they are available only 
for several samples from the Yakutian and African diamondiferous provinces, seem to reflect a single geochemical trend of mantle eclogite evolution.

4. It appears that a clear core of eclogite diamonds crystallized from melt whereas rims from a fluid phase supersaturated with carbonaceous inatter relative to diamond. The core-rim interface is a phase boundary whereat the solidus temperature of the system is attained. The medium evolved with decreasing $F$ and $T$, which was probably consistent with a rieing mantle diapir represented by, heterogeneous eclogite material.

5. High $\mathrm{K}_{2} \mathrm{O}$ content of omphacite inclusions in diamonds from various parts of the world may indicate their crystallization in the presence of a substantially high-potassium melt or fluid.

6. Recently, preliminary data on the U content of coated diamonds were obtained using f-radiography (I.I.Kashkarov, unpubI. data). The U content is $0.6 \pm 0 . I$ pm in clear cores of diamond. $>3$ - 7 ppm in delt inclusione, 50 - $100 \mathrm{ppm}$ in local cracks. The reaium from which dianonos crystallized seers to have been rich in $\mathrm{U}$.

7. Nethodclogically, the studied melt microinclusions represent a new type of inclurions. A local crack and a disordered graphite film which are related to such inclisions may be the result of partial degassing during kimberlite magmatism in the crust where $P_{f l}>P_{\text {tot }}$ was attained at the inclusion-matrix interface. These features can be used as visual indicators in choosing diamond crystals that are likely to contain primary nelt inclisions. 